\title{
Assurance des Médecins Suisses
}

\author{
Rolf O. Heimgartner, Directeur
}

Le 21 mai 2005 s'est déroulée la 79e Assemblée ordinaire des délégués de l'Assurance des Médecins Suisses sous la présidence de Monsieur le Docteur J. Fritzsche à l'Hôtel Palace de Lucerne.

Ont assisté à l'Assemblée 21 délégués, ainsi que Messieurs Peter W. Möschler, actuaire, Berne, Jakob Burkhard, directeur suppléant d'Ernst \& Young SA, Berne, Monsieur le Docteur Hans Furthmüller, CIO de la BCBE, Berne et Monsieur Fritz Jakober, gérant indépendant, Ennenda.

Les actions sur les grandes places boursières internationales ont su profiter d'un environnement conjoncturel plus avantageux et ont affiché une légère hausse. Les taux d'intérêts des obligations et hypothèques demeurent, eux, à un niveau très bas. Sur le front monétaire, l'euro et plus particulièrement le dollar américain, ont fléchis par rapport au franc suisse.

Le produit national brut (PNB) a reculé au cours du quatrième trimestre 2004. Selon les chefs économiciens suisses, le moteur économique suisse ne connaîtra pas de ratés importants en 2005 ceci, en dépit des faibles impulsions venant d'Allemagne, du prix élevé du pétrole et des faiblesses du dollar.

La somme du bilan a augmenté par rapport à l'année précédente, pour passer à Fr. 1018 229.-.

Le nombre de membres a lui aussi augmenté au cours de l'exercice 2004 .

Nos placements de capitaux se sont répartis de la manière suivante :

\begin{tabular}{ll} 
Titres à intérêts fixes & Fr. 488709 000.- \\
\hline Actions et fonds de placement & Fr. 61115 000.- \\
\hline Parts sur fondations de placement & Fr. 104761 000.- \\
\hline Immeubles & Fr. 168502 000.- \\
\hline Hypothèques & Fr. 131445000 .- \\
\hline Prêts sur polices & Fr. 1362 000.- \\
\hline Crédits d'investissement & Fr. $\quad 562000$.- \\
\hline Placements à long terme & Fr. 14000000 .-
\end{tabular}

Les réserves actuarielles se sont vues augmentées de Fr. 896912 000.- par rapport à l'année dernière, pour passer à Fr. 923735 000.-.

L'Assemblée des délégués a approuvé à l'unanimité le rapport de gestion, le bilan et le compte d'exploitation de l'exercice 2004 et a accordé sa décharge au Comité du Conseil d'administration, au Conseil d'administration et à la Direction, pour l'année écoulée.

Se ralliant à la proposition du Conseil d'administration, l'Assemblée des délégués a décidé, à l'unanimité, de répartir le bénéfice d'exploitation restant après bonification et répartition aux réserves, soit Fr. 543 425.-, de la manière suivante:

Attribution aux réserves générales Fr. 540000 .Attribution au fonds de secours \begin{tabular}{l} 
Fr. $3425 .-$ \\
\hline Fr. $543425 .-$
\end{tabular}

L'Assemblée des délégués a élu à l'unanimité ces messieurs du Conseil d'administration pour un nouveau mandat de 3 ans:

- Dr méd. Jürg M. Fritzsche, Président, Uetikon;

- Dr méd. Balthasar Leuzinger, Vice-président, Zurich;

- Dr méd. Rolf Lehmann, Worb;

- Dr méd. vét. Ulrich Friedli, Herzogenbuchsee;

- Prof. Dr méd. dent. Max O. Schmid, Unterentfelden.

Les organes de révision suivants ont été élus pour la période allant de l'Assemblée des délégués de l'année 2005 jusqu'à l'Assemblée des délégués de l'année 2006:

- Monsieur Peter W. Möschler, Berne, en tant qu'actuaire

- Ernst \& Young SA, Berne, pour le contrôle technique des comptes en tant qu'organe de révision.

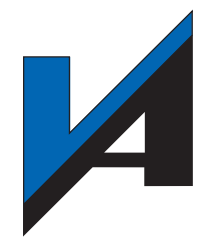

Correspondance:

Assurance des Médecins Suisses

Länggassstrasse 8

CH-3000 Berne 9

tél. 0313012555

fax 0313025156

E-mail: versa@versa.ch

Internet: www.versa.ch 